\title{
POTENSI TUMBUHAN BERKAYU GETAH MERAH PADA KAWASAN HUTAN BEMBAB KABUPATEN MANOKWARI SELATAN
}

\section{(The Potency of Red Sap Woody Plant Species in Bembab Forest Area of Manokwari Selatan District)}

\author{
Fransisca Patoding ${ }^{1}$, Rusdi Angrianto ${ }^{1}$ dan Hans F. Z. Peday ${ }^{1 凶}$ \\ Jurusan Kehutanan, Fakultas Kehutanan Universitas Papua Manokwari, Papua Barat, \\ 98314. Tlp/Fax: +62986211065. \\ $\triangle$ Penulis Korespondensi: Email: hans.peday@yahoo.com \\ Diterima: 21 Agust 2017| Disetujui: 15 Sept 2017
}

\begin{abstract}
Abstrak
Tujuan dari penelitian ini ialah untuk mengetahui potensi dan keragaman jenis tumbuhan bergetah merah di kawasan hutan Bembab Kabupaten Manokwari Selatan dengan menggunakan metode deskriptif dengan kegiatan survey dan pengambilan data lapangan sesuai desain plot pengamatan. Hasil penelitian menunjukkan bahwa terdapat 15 jenis dari 7 genus dan 3 famili tumbuhan penghasil getah merah di kawasan hutan Bembab. Total kerapatan tumbuhan getah merah untuk semua fase pertumbuhan mencapai 5.038 individu per hektarnya dengan rata-rata kerapatan individu per hektarnya sebesar 336. Secara rinci, kerapatan jenis tumbuhan penghasil getah merah berkisar dari tingkat kerapatan tinggi hingga rendah sebagai berikut: Pometia coreace dengan 3117 individu, Intsia bijuga dengan 744 individu, Intsia palembanica dengan 385 individu, Pometia pinnata dengan 276 individu, Incarpus fagifer dengan 151 individu, Myristica fatua dengan 107 individu, Myristica subumbrans dengan 98 individu, Pterocarpus indicus dengan 72 individu, Gymnacranthera farquhariana dengan 28 individu, Horsfildia sylvestris dengan 25 individu, Myristica subargantea dengan 17 individu, Horsfieldia iryana and Horsfieldia parviflora dengan 4 individu, dan juga Horsfieldia irya dengan hanya 1 individu.
\end{abstract}

Kata Kunci: Tanaman berkayu, getah merah, potensi dan kerapatan jenis, hutan Bembab.

\begin{abstract}
The aim of this study was to discover the potency and diversity of woody plant species that inherently contained red sap characteristic in Bembab forest by using descriptive method through field survey technique. The result discovered that there were 15 species from 7 genuses, and 3 families which belonged to red sap tree species in Bembab forest. The total density red sap woody plant species for the entire growing phases in Bembab forest were 5.038 species per hectare with the individual average density per species for all growing phases was 336 individu per hectare. In detail, species density of red sap woody species ranging from the very dense species to the rare were: Pometia coreace 3117, Intsia bijuga 744, Intsia palembanica 385, Pometia pinnata 276, Incarpus fagifer 151, Myristica fatua 107, Myristica subumbrans 98, Pterocarpus indicus 72, Gymnacranthera farquhariana 28, Horsfildia sylvestris 25, Myristica subargantea 17, Horsfieldia iryana and Horsfieldia parviflora 4, and also Horsfieldia irya 1.
\end{abstract}

Keywords: Woody plants, red sap, species potency and diversity, Bembab forest.

101

@ Asosiasi Peneliti Biodiversitas Papuasia - Fakultas Kehutanan UNIPA 


\section{PENDAHULUAN}

Hutan merupakan suatu kumpulan tumbuhan dan juga tanaman, terutama pepohonan atau tumbuhan berkayu lain, yang menempati daerah yang cukup luas. Pohon sendiri adalah tumbuhan dengan pertumbuhan utama yang cukup tinggi dengan masa hidup bertahun-tahun. Pohon juga berbeda karena secara mencolok memiliki batang pokok berkayu yang berdiri tegak yang cukup panjang dan bentuk tajuk (mahkota daun) yang jelas (FAO 2016).

Indonesia memiliki $\pm 12,2$ juta hektar kawasan hutan yang merupakan bagian dari daerah fitogeografi malesia yang terkenal kaya akan jenis tumbuhannya. Pulau papua (bersama New Guinea dan Kepulauan Salomon) membentuk suatu wilayah fitogeografi tersendiri yang disebut papuasia. Kawasan ini memiliki keunikan tersendiri baik dari kekayaan jenis, marga maupun tingkat keendemikan yang tinggi dibandingkan dengan pulau-pulau lainnya di Indonesia.

Papua merupakan salah satu pulau terbesar di Indonesia yang memiliki potensi sumberdaya alam berupa tambang, minyak bumi dan gas serta sumberdaya alam berupa hutan yang memiliki keragaman jenis flora dan fauna yang sangat melimpah. Walaupun secara menyeluruh belum dapat tercover secara rinci potensi dan nilai diversitasnya, namun diperkirakan terdapat tumbuhan berkayu dengan jumlah berkisar antara 11.000 sampai 20.000 jenis (Kartikasari dkk. 2013). Papua memiliki hutan primer terluas dan terakhir di Indonesia dan merupakan nilai indemis satu gudang tumbuhan tropis terbesar di dunia yang tersisa sekarang, dan telah banyak memberi manfaat bagi pembangunan nasional maupun regional dengan produksi kayu maupun non kayu (Lekitoo dkk. 2017).

Kawasan hutan Bembab merupakan tipe hutan dataran rendah yang memiliki potensi flora dan fauna yang cukup beragam serta fisiografi wilayah yang unik.Karena keunikan fisiografi wilayah yang dicirikan oleh struktur geologi ditambah dengan kepadatan vegetasi hutan khususnya tumbuhan berkayu yang cukup tinggi. Salah satu upaya dalam menginformasikan potensi hutan khususnya jenis-jenis tumbuhan berkayu bergetah merah yaitu mendeskripsikan ciri-ciri organ vegetatif dan organ generatif agar dapat mengenal potensi flora tumbuhan di kawasan hutan bembab. Penelitian ini bertujuan untuk mengetahui keragaman jenis dan potensi jenis tumbuhan berkayu bergetah merah di kawasan hutan Bembab, di Kabupaten Manokwari Selatan.

\section{METODE PENELITIAN}

\section{Risalah Umum Kegiatan}

Penelitian ini dilaksanakan pada kawasan hutan Bembab Kabupaten Manokwari Selatan, Provinsi Papua Barat dan berlangsung selama \pm 2 Bulan, November 2016 s/d Januari 2017. Peralatan yang digunakan antara lain: kompas, Global Positioning System (GPS), meteran rol, mistar, phi band, parang, kamera, dan alat tulis menulis dan perlengkapan lapangan personal, sedangkan bahan antara lain tallysheet, dan spesimen (bagian-bagian tumbuhan). Yang menjadi obyek utama penelitian ini ialah semua jenis tumbuhan berkayu 
bergetah merah yang berada dalam jalur pengamatan di hutan Bembab.

\section{Metode dan Teknik Penelitian}

Metode yang digunakan dalam penelitian ini adalah metode deskripsi dengan teknik survei lapangan. Dimana data akan diperoleh secara langsung dari hasil inventarisasi dan kemudian dikelompokkan berdasarkan jenis dan spesies. Untuk penempatan plot pengamatan dibuat setelah ditemukan individu jenis tumbuhan berkayu bergetah merah. Penentuan plot pengamatan dilakukan secara purposif, dimana disetiap ketinggian dibuat plot dengan ukuran $2 \times 2 \mathrm{~m}$ untuk tingkat semai, $5 \times 5$ $\mathrm{m}$ untuk tingkat pancang, $10 \times 10 \mathrm{~m}$ untuk tingkat tiang dan $20 \times 20 \mathrm{~m}$ untuk tingkat pohon. Yang menjadi variabel dalam penelitian ini ialah: ciri morfologi jenis-jenis tumbuhan berkayu bergetah merah antara lain batang, daun, bunga, buah dan biji dengan variabel penunjang meliputi: keadaan umum kawasan hutan Bembab.

\section{Pengambilan Data}

Langka-langka pengumpulan data yang dilakukan dalam penelitian ini adalah sebagai berikut:

1. Menentukan titik awal (titik ikat) pengamatan menggunakan GPS.

2. Menentukan arah pengamatan dengan menggunakan kompas.

3. Membuat base line tegak lurus kontur dan jalur pengamatan sejajar kontur dengan interval ketinggian 0-50 m dpl, 50-100 m dpl, 100-150 m dpl, sampai dengan $300 \mathrm{~m}$ dpl. Petak pengamatan dibuat sebanyak 52 petak. Petak pengamatan ini dibuat ukuran 20x20 m tersebar pada \pm 7 petak pengamatan.

4. Menakik batang tumbuhan berkayu untuk mengetahui getah merah.

5. Mengukur diameter, tinggi bebas cabang dan tinggi total jenis tumbuhan berkayu getah merah.

6. Mencatat ciri morfologi dan mengukur bagian-bagian dari morfologi tumbuhan berkayu bergetah merah, mencatat kondisi habitat, mendokumentasikan setiap jenis tumbuhan berkayu bergetah merah.

\section{Pengolahan Data}

Data hasil penelitian yang telah dikumpulkan kemudian diolah untuk mendapatkan nlai Indeks Nilai Penting (INP) yang berguna untuk menentukan dominasi jenis tumbuhan berkayu yang terdapat pada kawasan hutan Bembab. Nilai ini diperoleh dari penjumlahan kerapatan relatif, frekuensi relatif dan dominansi relatif. Sehingga selanjutnya dapat mengetahui potensi tumbuhan berkayu yang berada pada hutan Bembab. INP diketahui dengan menggunakan rumus perhitungan analisis vegetasi menurut Soerianegara dan Indrawan (2005), sebagai berikut:

1. Kerapatan $(\mathrm{K})$ dan Kerapatan Relatif (KR)

Kerapatan merupakan jumlah individu spesies per satuan luas ruang. Kerapatan spesies ke- $i$ dapat dihitung sebagai $\mathrm{K}-i$ dan kerapatan relatif setiap spesies ke- $i$ terhadap kerapatan total dapat dihitung sebagai KR-i. Rumus untuk menghitung kerapatan dan kerapatan relatif adalah sebagai berikut:

$\operatorname{Kerapatan}(K)=$ $\frac{\text { Tumlah individu swatijenis }}{\text { Luas plot contoh }} \ldots n / h$ h

Kerapatan Relatif $(K R)=$ 
Kerapatan darisuatujenis Kerapatan seluruh jenis<smiles>[R]OC(=O)O</smiles>

2. Frekuensi (F) dan Frekuensi Relatif (FR)

Frekuensi merupakan proporsi antara jumlah plot sampel yang berisi suatu spesies tertentu terhadap total jumlah plot sampel dengan nilai frekuensi dapat menggambarkan tingkat penyebaran dan pola sebaran spesies di dalam habitatnya. Rumus dari Frekuensi (F) dan Frekuensi Relatif adalah sebagai berikut: Frekuensi $(\mathrm{F})=$

Jumlah plot ditenukan suatujenis Jumlah seluruh plot

Frekuensi Relatif $($ FR $)=$

$\frac{\text { Frekwensi swatu jenis }}{\text { Frekuensi seluruh jevis }} \times 100 \%$

3. Luas Bidang Dasar (LBD)

Luas bidang dasar (LBD) adalah luas penampang lingkaran diameter batang. Rumus untuk menghitung Luas Bidang Dasar adalah:

$$
\mathrm{LBD}=1 / 4 \pi(\mathrm{D} / \mathbf{1 0 0})^{2}
$$

Dimana: $\mathrm{LBD}=$ Luas Bidang Dasar $\left(\mathrm{m}^{2}\right)$ $1 / 4 \pi=$ Konstanta $(\mathrm{m}) ; \mathrm{D}=$ Diameter (cm).

4. Dominansi (D) dan Dominansi Relatif (DR)

Dominansi merupakan proporsi antara luas tempat yang ditutupi oleh spesies tumbuhan dengan luas total habitat. Luas penutupan dapat dinyatakan dengan menggunakan luas bidang dasar (basal area).
Dominansi $(\mathrm{D})=$

Ebidang dasne suatu jenis luas plot contoh

Dominasi Relatif $(\mathrm{DR})=$

$\frac{\text { dominasi suatujenis }}{\text { dominasi seluruhjenis }} \times 100 \%$

5. Indeks Nilai Penting (INP)

Indeks Nilai Penting (INP) atau importance value index adalah parameter kuantitatif yang dapat dipakai untuk menyatakan tingkat dominansi atau penguasahaan spesies-spesies dalam suatu komunitas tumbuhan dengan kriteria semakin tinggi nilai INP suatu spesies, semakin dominan atau berkuasa suatu spesies dalam suatu komunitas tumbuhan. Rumus Indeks Nilai Penting (INP) untuk masing-masing tingkat pertumbuhan sebagai berikut:

a. Untuk tingkat permudaan (semai dan pancang)

$$
\text { INP }=\text { KR }(\%)+\text { FR }(\%)
$$

b. Untuk tingkat tiang dan pohon

$$
\text { INP }=\text { KR }(\%)+\text { FR }(\%)+\text { DR }(\%)
$$

$$
\begin{aligned}
\text { Dimana: INP } & =\text { Indeks Nilai Penting } \\
\text { KR } & =\text { Kerapatan Relatif } \\
\text { FR } & =\text { Frekuensi Relatif } \\
\text { DR } & =\text { Dominansi Relatif }
\end{aligned}
$$

\section{Analisis Data}

Data yang diperoleh kemudian dianalisis secara tabulasi dan disajikan secara deskripsi mengenai bagian-bagian morfologi yang telah diperoleh disertai foto atau gambar. 


\section{HASIL DAN PEMBAHASAN}

Secara umum kawasan hutan Bembab merupakan kawasan hutan tropis dataran rendah dengan kisaran ketinggian tempat berkisar antara $0-300 \mathrm{~m}$ di atas permukaan laut (dpl). Kawasan ini berbatasan langsung dengan garis pantai yang berada di sebelah timur kawasan dan puncak yang terletak di tengah kawasan. Topografi pada kawasan hutan ini bervariasi yaitu dari landai, bergelombang ringan, agak curam hingga curam dengan kemiringan yang bervariasi dari 8 - 75\%. Jumlah jalur pengamatan terdiri dari 6 jalur yang tersebar berdasarkan kondisi ketinggian, yaitu antara 0 - $50 \mathrm{~m} \mathrm{dpl,} 50$ - $100 \mathrm{~m} \mathrm{dpl}, 100$ $150 \mathrm{~m}$ dpl, 150 - $200 \mathrm{~m} \mathrm{dpl,} 200$ - $250 \mathrm{~m}$ dpl dan 250 - $300 \mathrm{~m}$ dpl dan dengan jumlah plot pengamatan sebanyak 52 plot.

Potensi jenis tumbuhan berkayu getah merah yang ditemukan di areal penelitian kawasan hutan Bembab terdiri atas 15 jenis spesies yang berasal dari 3 famili. Jenis dan famili tumbuhan berkayu getah merah yang ditemukan secara umum tidak merata pada setiap fase pertumbuhan dan ketinggian yang berbeda.

\section{Komposisi Jenis Tumbuhan Berkayu Getah Merah}

Secara umum berdasarkan hasil pengamatan pada lokasi penelitian di kawasan Gunung Bembab ditemukan 15 jenis spesies tumbuhan bergetah merah yang berasal dari 7 genus dan 3 famili. Jenis spesies tumbuhan bergetah merah yang terdapat di kawasan hutan Bembab terdiri dari 15 jenis spesies, yaitu
:Gymnacranthera

farquhariana, Horsfieldia irya, Horsfieldia iryana, Horsfieldia laevigata, Horsfieldia parviflora, Horsfieldia sylvestris, Inocarpus fagifer, Intsia bijuga, Intsia palembanica, Myristica fatua, Myristica subargentea, Myristica subumbrans, Pometia coreacea, Pometia pinnata dan Pterocarpus indicus. Sedangkan 7 genusnya, yaitu : Gymnacranthera, Horsfieldia, Inocarpus, Intsia, Myristica, Pometia dan Pterocarpus dan termasuk ke dalam 3 famili, yaitu: Myristicaceae, Fabaceae dan Sapindaceae.

Selain itu jenis tumbuhan berkayu bergetah merah ini umumnya ditemukan pada daerah yang mempunyai topografi agak datar, yaitu area-area cekungan pada kemiringan lereng yng cukup curam. Kondisi ini disebabkan karena buah dari tumbuhan bergetah merah umumnya berbentuk bulat dan bulat lonjong, pada saat masak akan jatuh mengikuti kondisi lansekap pada lokasi tumbuhnya. Selain itu jenis-jenis dari marga Pometia, pada saat berkecambah atau proses pertumbuhan benih mencapai fase semai sangat membutuhkan cahaya (intoleran) dengan kelembaban yang sesuai. Faktor lainnya adalah buahnya disukai sebagai pakan atau makanan oleh hewan atau satwa liar, sehingga secara alami penyebaran jenis tersebut sangat ditentukan oleh pergerakan dari hewanhewan liar tersebut. Kondisi ini mengakibatkan pada saat pengamatan, plot-plot ditemukan tumbuhan berkayu getah merah untuk fase semai dan fase pancang di bawah pohon induk jumlahnya lebih sedikit. 
Tabel 1. Jumlah jenis tumbuhan berkayu getah merah berdasarkan fase pertumbuhan di kawasan hutan Bembab.

\begin{tabular}{lccccc}
\hline Famili & \multicolumn{3}{c}{ Fase Pertumbuhan/Jumlah Jenis } & \multirow{2}{*}{ Total Jenis } \\
\cline { 2 - 5 } & Semai & Pancang & Tiang & Pohon & \\
\hline Fabaceae & 4 & 4 & 2 & 4 & 4 \\
Myristicaceae & 1 & 5 & 8 & 5 & 9 \\
Sapindaceae & 2 & 2 & 2 & 2 & 2 \\
\hline
\end{tabular}

Sumber : Data Primer, 2017

Berdasarkan Tabel 1, terlihat bahwa tumbuhan berkayu getah merah yang ditemukan pada kawasan hutan Bembab terdiri dari 3 famili, yaitu famili Fabaceae, Myristicaceae dan Sapindaceae. Famili tumbuhan berkayu getah merah yang keragaman jenisnya paling banyak ditemukan untuk semua fase pertumbuhan adalah famili Myristicaceae dengan jumlah jenis sebanyak 9 jenis, disusul famili Fabaceae dengan jumlah jenis sebanyak 4 spesies, dan diikuti famili Sapindaceae dengan jumlah jenis sebanyak 2 spesies. Keragaman jenis spesies di dalam suatu famili sangat terkait dengan kondisi ekologi habitat tempat tumbuh dan proses evolusi yang terjadi dalam jangka waktu yang lama. Guna mengetahui potensi individu per satuan luasan kawasan tumbuhan bergetah merah berdasarkan fase pertumbuhan di kawasan hutan Bembab disajikan pada Tabel 2. Tabel 2 menunjukkan bahwa kerapatan total jenis tumbuhan bergetah merah untuk semua fase pertumbuhan di kawasan gunung Bembab mencapai 5.038 individu per hektar dengan rata-rata kerapatan individu per jenis untuk seluruh fase pertumbuhan adalah 336 individu per hektar.

Bila dilihat dari kerapatan per jenis dan per fase pertumbuhan, maka untuk jenis tumbuhan bergetah merah yang memiliki tingkat kerapatan tertinggi pada fase pertumbuhan semai adalah jenis Pometia coreacea dengan kerapatan individu per hektar sebesar 3.029 individu per hektar, diikuti Intsia bijuga dengan kerapatan individu per hektar sebesar 577 individu per hektar, di urutan ketiga terdapat jenis Intsia palembanica dan Pometia pinnata dengan kerapatan masing-masing individu per hektar sebesar 240 individu per hektar, di urutan keempat terdapat jenis Inocarpus fagifer dengan kerapatan individu per hektar sebesar 96 individu per hektar dan jenis dengan kerapatan terendah pada fase semai adalah Myristica fatua dan Pterocarpus indicus dengan kerapatan individu per hektar sebesar 48 individu per hektar. Ada juga jenis yang tidak ditemukan individunya di dalam plot pengamatan, yaitu : Gymnacranthera farquhariana, Horsfieldia irya, Horsfieldia iryana, Horsfieldia laevigata, Horsfieldia parviflora, Horsfieldia sylvestris, Myristica subargentea, Myristica subumbrans.

Kerapatan individu pada fase semai sangat di dominasi oleh marga pometia dan intsia. Hal ini disebabkan oleh kemampuan kedua marga tersebut dalam menghasilkan benih yang banyak dalam satu musim perbungaan dan pembuahan dimana kondisi ini juga dipengaruhi oleh sifat daya kecambah (viabilitas) dari biji yang dihasilkan. Dimana sifat dormansi dari marga pometia sangat singkat, akan 
berkecambah dengan cepat apabila terdapat hujan (dormansi kurang dari 10 hari), sedangkan pada marga Intsia, dormansi bijinya dapat mencapai lebih dari 1 tahun.

Tabel 2. Kerapatan individu (individu/hektar) tumbuhan bergetah merah berdasarkan famili dan fase pertumbuhan di kawasan hutan Bembab.

\begin{tabular}{|c|c|c|c|c|c|c|}
\hline \multirow{2}{*}{ No. } & \multirow{2}{*}{ Nama Latin } & \multicolumn{4}{|c|}{ Fase Pertumbuhan } & \multirow{2}{*}{ Total } \\
\hline & & Semai & Pancang & Tiang & Pohon & \\
\hline & Famili Myristicacea: & & & & & \\
\hline 1 & Gymnacranthera farquhariana & 0 & 23 & 4 & 1 & 28 \\
\hline 2 & Horsfieldia irya & 0 & 0 & 0 & 1 & 1 \\
\hline 3 & Horsfieldia iryana & 0 & 0 & 4 & 0 & 4 \\
\hline 4 & Horsfieldia laevigata & 0 & 8 & 4 & 0 & 12 \\
\hline 5 & Horsfieldia parviflora & 0 & 0 & 4 & 0 & 4 \\
\hline 6 & Horsfieldia sylvestris & 0 & 23 & 2 & 0 & 25 \\
\hline 7 & Myristica fatua & 48 & 46 & 12 & 1 & 107 \\
\hline 8 & Myristica subargentea & 0 & 15 & 2 & 0 & 17 \\
\hline \multirow[t]{2}{*}{9} & Myristica subumbrans & 0 & 69 & 27 & 1 & 98 \\
\hline & Famili Fabaceae: & & & & & \\
\hline 10 & Inocarpus fagifer & 96 & 54 & 0 & 1 & 151 \\
\hline 11 & Intsia bijuga & 577 & 154 & 8 & 5 & 744 \\
\hline 12 & Intsia palembanica & 240 & 131 & 12 & 2 & 385 \\
\hline \multirow[t]{2}{*}{13} & Pterocarpus indicus & 48 & 23 & 0 & 0 & 72 \\
\hline & Famili Sapindaceae: & & & & & \\
\hline 14 & Pometia coreacea & 3029 & 54 & 13 & 21 & 3117 \\
\hline \multirow[t]{3}{*}{15} & Pometia pinnata & 240 & 31 & 2 & 3 & 276 \\
\hline & Jumlah Total & 4279 & 631 & 88 & 39 & 5038 \\
\hline & Jumlah Rata-Rata & 285 & 42 & 6 & 3 & 336 \\
\hline
\end{tabular}

Sumber : Data Primer, 2017

Jenis tumbuhan bergetah merah yang memiliki tingkat kerapatan tertinggi pada fase pertumbuhan pancang adalah jenis Intsia bijuga dengan kerapatan individu per hektar sebesar 154 individu per hektar, diikuti Intsia palembanica dengan kerapatan individu per hektar sebesar 131 individu per hektar, di urutan ketiga terdapat jenis Myristica subumbrans dengan kerapatan individu per hektar sebesar 69 individu per hektar, di urutan keempat terdapat jenis Inocarpus fagifer dan Pometia coreacea dengan kerapatan individu per hektar sebesar 54 individu per hektar, di urutan berikut terdapat jenis Myristica fatua dengan kerapatan individu per hektar sebesar 46 individu per hektar, Pometia pinnata dengan kerapatan individu per hektar sebesar 31 individu per hektar, Gymnacranthera farquhariana dan Pterocarpus indicus dengan kerapatan individu per hektar sebesar 23 individu per hektar, Myristica 
subargentea dengan kerapatan individu per hektar sebesar 15 individu per hektar, dan jenis dengan kerapatan terendah pada fase pancang adalah Horsfieldia laevigata dengan kerapatan individu per hektar sebesar 8 individu per hektar. Ada juga jenis yang tidak ditemukan individunya di dalam plot pengamatan, yaitu: Horsfieldia irya, Horsfieldia iryana, Horsfieldia parviflora. Pada fase pancang terjadi perubahan dominasi kerapatan, yang mana diduga sangat dipengaruhi oleh kemampuan adaptasi jenis yang berkaitan dengan sifat toleransi jenis tersebut.

Jenis tumbuhan bergetah merah yang memiliki tingkat kerapatan tertinggi pada fase pertumbuhan tiang adalah jenis Myristica subumbrans dengan kerapatan individu per hektar sebesar 27 individu per hektar, diikuti Pometia coreacea dengan kerapatan individu per hektar sebesar 13 individu per hektar, di urutan ketiga terdapat jenis Myristica fatua dan Intsia palembanica dengan kerapatan individu per hektar sebesar 240 individu per hektar, di urutan keempat terdapat jenis Intsia bijuga dengan kerapatan individu per hektar sebesar 8 individu per hektar, di urutan kelima terdapat jenis Gymnacranthera farquhariana, Horsfieldia iryana, Horsfieldia laevigata, Horsfieldia parviflora dan jenis dengan kerapatan terendah pada fase tiang adalah Horsfieldia sylvestris dan Pometia pinnata dengan kerapatan individu per hektar sebesar 48 individu per hektar. Ada juga jenis yang tidak ditemukan individunya di dalam plot pengamatan, yaitu : Horsfieldia irya, Inocarpus fagifer, Pterocarpus indicus. Hal yang sama juga terjadi pada fase tiang, dimana terjadi perubahan dominasi kerapatan, diduga dipengaruhi oleh hal yang sama, yaitu kemampuan adaptasi jenis yang berkaitan dengan sifat toleransi dan intoleransi jenis tersebut.

Jenis tumbuhan bergetah merah yang memiliki tingkat kerapatan tertinggi pada fase pertumbuhan pohon adalah jenis Pometia coreacea dengan kerapatan individu per hektar sebesar 21 individu, diikuti Intsia bijuga dengan kerapatan individu per hektar sebesar 5 individu, di urutan ketiga terdapat jenis Pometia pinnata dengan kerapatan individu per hektar sebesar 3 individu, di urutan keempat terdapat jenis Intsia palembanica dengan kerapatan individu per hektar sebesar 2 individu per hektar dan jenis dengan kerapatan terendah pada fase pohon adalah Gymnacranthera farquhariana, Horsfieldia irya, Myristica fatua, Myristica subumbrans, Inocarpus fagifer dengan kerapatan individu per hektar sebesar 1 individu. Ada juga jenis yang tidak ditemukan individunya di dalam plot pengamatan, yaitu: Horsfieldia iryana, Horsfieldia laevigata, Horsfieldia parviflora, Horsfieldia sylvestris, Myristica subargentea dan Pterocarpus indicus. Hal yang sama juga terjadi pada fase pohon, dimana terjadi perubahan dominasi kerapatan, diduga dipengaruhi oleh hal yang sama, yaitu kemampuan adaptasi jenis yang berkaitan dengan sifat toleransi dan intoleransi jenis tersebut.

Dilihat dari famili maka total kerapatan tertinggi adalah famili Sapindaceae pada jenis Pometia coreacea dengan total kerapatan sebesar 3117 per hektar, kemudian jenis Pometia pinnata dengan total kerapatan terendah sebesar 276 per hektar. Diikuti famili Fabaceae pada jenis Intsia bijuga dengan total kerapatan tertinggi 744 per hektar, jenis Intsia palembanica dengan total 385 per 
hektar, jenis Inocarpus fagifer dengan total kerapatan sebesar 151 per hektar dan jenis Pterocarpus indicus dengan total kerapatan terendah sebesar 72 per hektar. Total kerapatan terendah adalah famili Myristicacea pada jenis Myristica fatua sebesar 107, jenis Myristica subumbrans sebesar 98, jenis Gymnacranthera farquhariana sebesar 28, jenis Horsfieldia sylvestris sebesar 25, jenis Horsfieldia laevigata sebesar 12, jenis Horsfieldia iryana dan Horsfieldia parviflora sebesar 4 dan jenis Horsfieldia irya dengan total terendah sebesar 1 per hektar.

Faktor-faktor ekologi atau faktorfaktor lingkungan yang mungkin diperebutkan oleh tumbuhan dalam persaingan antara lain cahaya, air tanah, oksigen, unsur hara, dan karbon dioksida. Faktor-faktor eksternal lainnya, seperti kehadiran hewan penyerbuk, agen dispersal biji, kondisi tanah, kelembaban tanah dan udara, angin dan gangguan atau kerusakan lingkungan oleh manusia juga berpengaruh terhadap kelangsungan hidup dari spesies-spesies tertentu di suatu habitat (Vickery 1984).

Penggantian spesies tumbuhan tertentu oleh spesies lain di suatu habitat sangat bergantung kepada kemampuan spesies tumbuhan untuk bersaing dengan yang lain terhadap tempat (ruang tumbuh), cahaya, air dan unsur hara tanah. Pada tempat-tempat dengan kondisi ekstrem (keras) seperti di padang pasir dan lingkungan montane, umumnya tumbuhan tumbuh berjarak cukup lebar antara individu, sehingga mengurangi tingkat persaingan yang terjadi. Akan tetapi, pada kondisi yang ideal seperti di hutan hujan tropis, persaingan yang terjadi sangat keras dan tumbuhan akan mempunyai kemampuan adaptasi pada banyak niche ekologi yang berbeda untuk kelangsungan hidupnya.

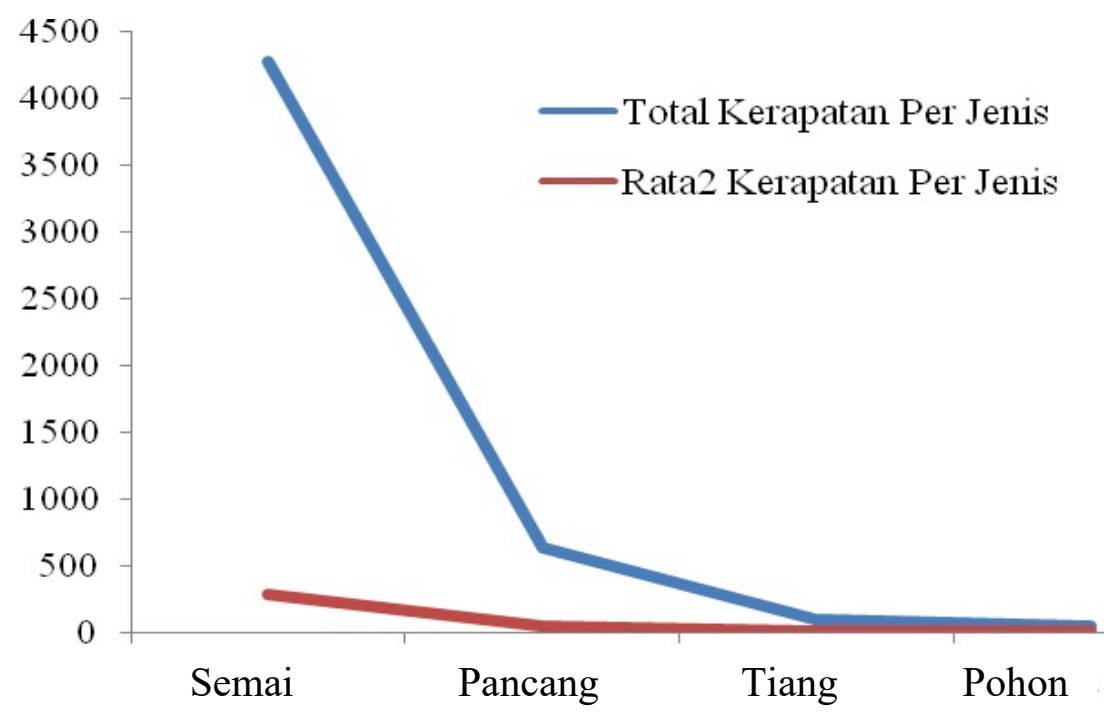

Gambar 1. Grafik persentase penurunan kerapatan pada fase pertumbuhan tumbuhan berkayu getah merah. 
Pada Gambar 1, menunjukkan penurunan sangat tajam dan membentuk huruf ' $\mathrm{J}$ ' terbalik. Hal ini dapat dilihat dari total kerapatan per hektar pada fase semai ke pancang mengalami penurunan sebesar $85,25 \%$, kemudian total kerapatan per hektar pada fase pancang ke tiang mengalami penurunan sebesar $86,05 \%$, dan pada fase tiang ke pohon mengalami penurunan yang sangat tajam sebesar $55,68 \%$. Pada kondisi ini sebenarnya persentase penurunan jumlah individu dari fase pertumbuhan satu ke yang lainnya dapat dikatakan ideal yang terjadi pada pertumbuhan hutan secara normal pada hutan alam.

Untuk persentase rata-rata per hektar pada fase semai ke pancang mengalami penurunan sebesar $85,26 \%$, kemudian rata-rata per hektar pada fase pancang ke tiang mengalami penurunan sebesar $85,71 \%$, dan pada fase tiang ke pohon mengalami penurunan yang sangat tajam sebesar $50,00 \%$. Rata-rata penurunan potensi per hektar yang terjadi, terutama pada tingkat tiang ke tingkat pohon yang hanya mencapai $50 \%$ dapat dikatakan normal karena tidak terjadi pembeda yang signifikan pada strata B ke strata A.

\section{DAFTAR PUSTAKA}

FAO. 2016. Trees, forests, and land use in drylands. The first global assessment. Preliminary Findings. Food and Agriculture Organization of the United Nations, Rome.

Kartikasari EN, Marshall AJ and Beehler BM. 2013. Ekologi papua. Jakarta: Yayasan Pustaka Obor Indonesia dan Conservation Internasional.

Lekitoo K, Peday HFZ, Panambe N and Cabuy RL. 2017. Ecological and ethnobotanical facet of 'Kelapa Hutan' (Pandanus spp.) and perspectives towards its existence and benefit. International Journal of Botany, 13: 103-114.

Soerianegara I dan A Indrawan. 2005. Ekologi hutan indonesia. Fakultas Kehutanan Institut Pertanian Bogor. Bogor.

Vickery ML.1984. Ecology of tropical plants. John Wiley and Soris. New York. HLM. 56-76. Penerbit Yayasan Obor Indonesi. 